\title{
Investigation of Corrosion of Buried Oil Pipeline by the Electrical Geophysical Methods
}

\author{
EKINE, A. S.; EMUJAKPORUE, G. O. \\ Department of Physics, University of Port Harcourt, Nigeria \\ E-mail: asekine2001@yahoo.co.uk
}

\begin{abstract}
The delineation of possible areas of corrosion along an underground oil pipeline in Ubeji, Delta State, Nigeria was investigated using the horizontal electrical resistivity profiling technique and the Spontaneous Potential geophysical method. The resistivity and self potential values of the soil along the pipeline were obtained using the R-plus resistivity meter. The results show that areas of low resistivity, having values between 98.0 and $116.0 \mathrm{Ohm}-\mathrm{m}$, coincide with areas of high negative spontaneous potential values, in the range -31.0 to $-52 \mathrm{mV}$. The low apparent resistivity and high negative spontaneous potential values are indications that the soil is very corrosive and there is the possibility of the pipeline failure and oil spillage around these hot spots in the future. These methods applied in the study are quick, economic and efficient for detecting likely anodic hot spots along buried pipelines which need to be protected. Routine electrical geophysical investigations along buried oil pipelines should be undertaken for the early detection and prevention of pipeline failure with its attendant environmental, human and economic consequences. @ JASEM
\end{abstract}

Corrosion is the gradual chemical attack and degradation that results in the conversion of metallic materials into oxides, salts or other compounds. Materials such as metals and its alloys (e.g. steel) that have undergone corrosion lose their strength, ductility and other mechanical properties. Corrosion attacks are frequently responsible for most materials failures. Corrosion of underground metallic materials is a very widespread problem. Structures such as natural gas and crude oil pipelines and water pipes are some of the structures reported to have been affected by soil corrosion all around the world (Levlin, 1992; Ovri and Ofeke, 1998; Rim-ruken and Awatefe, 2006; Chukwu et al., 2008). The failure of gas, crude oil pipeline or water pipe fails, is usually accompanied by high degree of environmental, human and economic consequences (Okoroafor, 2004).

The major cause of the deterioration of underground pipeline is the soil. Soil corrosion is caused by moisture, $\mathrm{pH}$, redox potential, microbes in soils and soil type. Underground pipe corrosion can be investigated with electrical geophysical methods such as electrical resistivity and potential methods (Parasnis, 1986). These methods are used to detect areas of high corrosion (hot spots) along the buried underground pipeline. The corrosivity of soils is nearly inversely proportional to their resistivity; that is low resistivity, means a high probability of corrosion (Andrew et al, 2005). Resistivity and spontaneous potential are two electrical properties of sedimentary rocks commonly measured. Taken individually, each set of data is inconclusive, but taken together these two measurements provide a good indication of some important lithologic distinctions in the subsurface (Emujakporue, 2003). This study was therefore undertaken to demonstrate the effectiveness of the proposed geophysical tools in the delineation of possible areas of underground oil pipeline corrosion that may result in unpleasant human, environmental and economic consequences.

Regional Geology of the Study Area: The study area, Ubeji, is located within Delta State, Nigeria, at a surface location of 366,140.12 m Easting and $174,200.08 \mathrm{~m}$ Northing. The geology of the area is typical of Niger Delta flood plains. It is a mostly seasonal swamp forest region. The area is underlain by the Quaternary to Tertiary sediments of the Benin Formations. The sediments in this region are typically sandy, silty, pebbly, loose, and poorly sorted. Groundwater potentials are very high due to high permeability, high recharge potential, and considerable aquifer thickness. The result of meteorological studies in the area (Gobo, 1998) shows the average atmospheric temperature to be $25.5^{\circ} \mathrm{C}$ in the rainy season and $30.10^{\circ} \mathrm{C}$ in the dry season. The daily relative humidity values ranged from 55.5 percent in the dry season to 96 percent in the rainy season. Analysis of monthly rainfall data indicates that the lowest rainfall average values of $25.33 \mathrm{~mm}$ occurs in the dry season and $314.82 \mathrm{~mm}$ in the rainy season.

Electrical Geophysical Methods for Underground Pipeline Corrosion Survey: The electrical properties of the subsurface can be explored by several geophysical methods. The two electrical methods commonly used are the Spontaneous Potential (SP) and the electrical resistivity techniques. The electrical resistivity method is commonly used for the delineation of horizontal and vertical discontinuities in the electrical properties of the subsurface and also for the detection of three - dimensional bodies of anomalous electrical conductivity. In the electrical resistivity method, artificially generated currents are introduced into the ground, and in the presence of variations in the conductivity of subsurface layers, the current flow path is altered which affects 
the electric potential distribution, and the resulting potential differences are measured at the surface.

The Self potential method makes use of natural currents flowing in the ground that are generated by electrochemical and electrokinetic processes, to locate shallow bodies of anomalous conductivity. The corrosivity of soils is inversely related to the soil resistivity, with low resistivity indicating high probability of corrosion. Table 1 , below is a general guide to classification of soil corrosivities by measured resistivity values. Certain natural or spontaneous potentials occurring in the subsurface are caused by electrochemical or mechanical activity. The controlling factor in all cases is underground fluids. These potentials are associated with variation in rock properties (mineral contents) at geological contacts, bioelectric activity of organic material, corrosion, thermal and pressure gradients in underground fluids and other phenomena of similar nature.

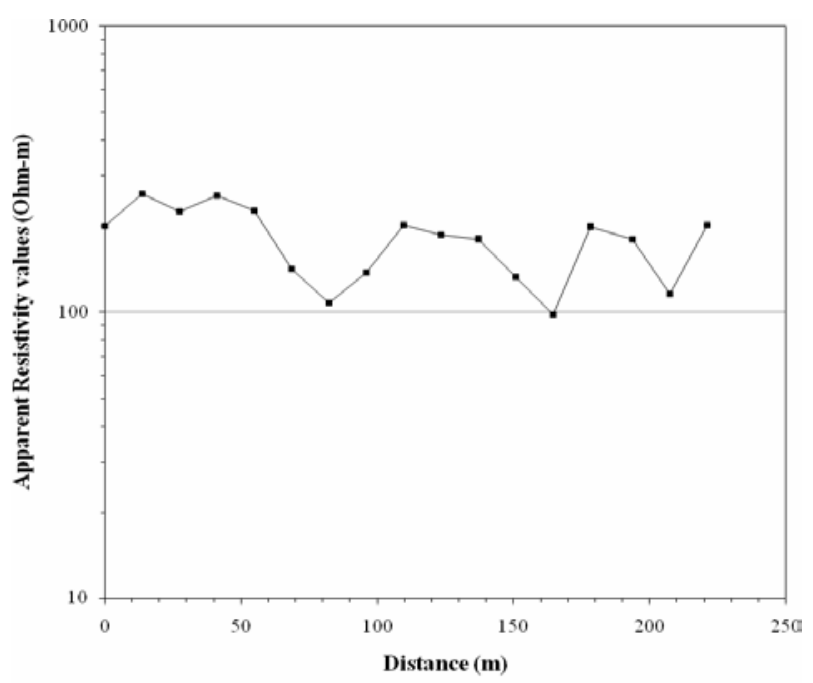

Fig 1: Plot of Apparent Resisitivity versus Distance along pipeline.

\section{RESULTS AND DISCUSSION}

The apparent resistivity and spontaneous potential profiles along the pipeline are shown respectively on Figures 1 and 2. From the spontaneous potential profile, areas of low (negative) potential values can easily be identified. There are three of such points within the length investigated with potential values between -31 and $-52 \mathrm{mV}$. These areas are probable anodic points, where metal iron entered into the solution and gave out electrons. The $\mathrm{Fe}^{2+}$ given out
Table 1.: Classification of soil corrosivity by resistivity (http://www.testing-engineers. Com/ case study 1. html)

\begin{tabular}{ll}
\hline Soil resistivity $(\mathrm{Ohm}-\mathrm{cm})$ & Corrosion tendency \\
\hline$<1500$ & Very Corrosive \\
$1500-5000$ & Corrosive \\
$10000-25000$ & Moderate \\
$>25000$ & Not Corrosive \\
\hline
\end{tabular}

Data Acquisition, Analysis and Presentation: The Wenner array electrodes configuration was employed for the data acquisition using the R-plus resistivity meter. This equipment has the ability to display apparent resistivity and self-potential values directly on the screen. It also has the advantage of portability and ability to compensate for polarization at the electrodes. The horizontal profiling techniques of the electrical resistivity methods of geophysics was used for determining lateral variations of resistivity using an electrodes spacing of 30.0 feet (about 10 metres), along the path of an oil pipeline, which was buried at a depth of about 10.0 feet (about 3.0 metres). The resistivity and spontaneous potential values, simultaneously displayed on the screen, were recorded. The data obtained from the field were plotted against the electrode spacing on a log-linear and linear-linear scales for the resistivity and selfpotential respectively as shown in Figures 1 and 2.

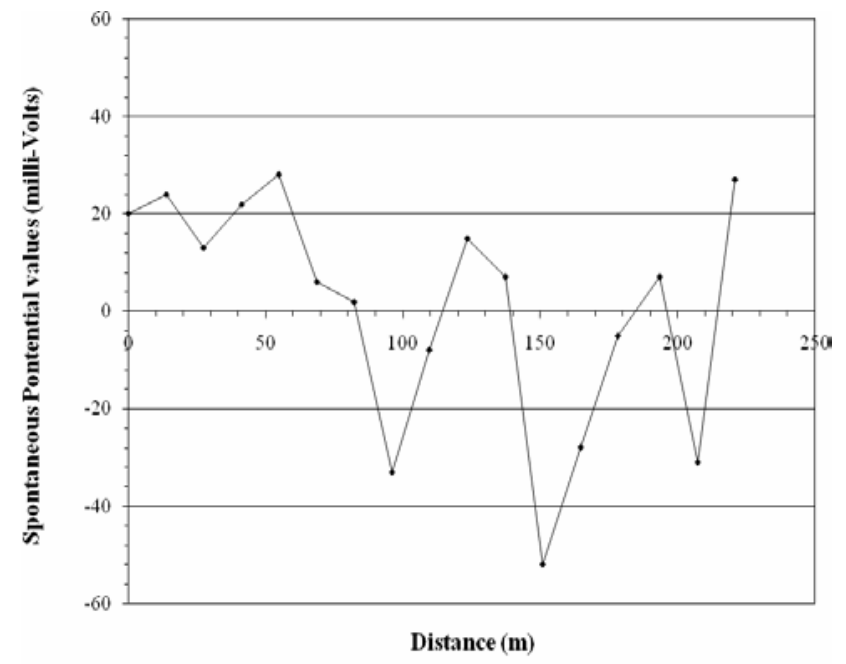

Fig 2: Plot of Spontaneous Potential versus Distance along Pipeline

combined with oxygen in the electrolyte to form rust (corrosion). These are the areas where corrosion is highly probably. The other areas along the profile where the spontaneous potential values are positive are spots where the electrons from the anode are absorbed (cathode). Similarly, along the resistivity profile, spots of low apparent resistivities are associated with high conductivity. Three of such relatively low resistivity areas were similarly identified. These areas have apparent resistivity 
values between 98.0 and 116.0 Ohm-m. These areas are interpreted as zones where chemical reaction (corrosion) is taking place, as a result of the chemical reaction in the subsurface between the pipe and the environment. Comparism of both the apparent resistivity and spontaneous potential profiles reveal that the zones of low soil apparent resistivity correspond to zones of high negative spontaneous potential values. Thus, zones of low apparent resistivities which are associated with high negative spontaneous potential values are consequently areas of high corrosivity according to Table 1. These zones also correspond to areas of poorly aerated wet clays (soil) and possible spots for pipeline failure and oil spillage.

Conclusion: The effectiveness of the electrical methods of geophysical investigation, which have been very well recognized as effective, quick, reliable and economic means of obtaining details about electrical characteristics of the subsurface at any location, has been demonstrated by this study. The results of the survey show that areas of high corrosivity are indicated by low electrical resistivity and high negative spontaneous potential values. The results also show that the soil is very corrosive, in terms of the classification in Table 1. The above methods are therefore very useful for the early detection of incipient pipeline corrosion, which in turn will assist in the prevention of the associated consequences of pipeline failure. It is hereby recommended that routine electrical geophysical surveys along buried pipeline environment should be encouraged to avoid possible pipeline failures. It is pertinent here to state that pipelines in the area of study should be protected by proper protective system to avoid any corrosive interaction between steel surface and soil environment.

\section{REFERENCES}

Andrew, ER; Graham, ECB; Sleven, JD; Foreman, $\mathrm{S}$ and American Water Works Association (AWWA) Research Foundation, (2005). External corrosion and corrosion control of buried water mains. American water works Ass. 159p.

Chukwu, GU; Ekine, AS; and Ebeniro, JO, (2008). SP anomalies around Abakaliki anticlinorum of southeastern Nigeria. Pacific J. Sci. and Tech., 9(2): $561-566$.

Emujakporue, OG, (2003). The correlation of Spontaneous Potential and Apparent Resistivity data from surface vertical electrical sounding in parts of Rivers state, Nigeria. Unpublished M. Sc. Thesis, University of Port Harcourt.

Gobo, AE, (1998). Meteorology and Man's Environment. Ibadan: African-link Books, 101-127

Levlin, E, (1992). Corrosion of water pipe systems due to acidification of soil and groundwater. Department of Applied Electro-chemistry and Corrosion Science, Royal Institute of Technology, Stockholm.

Okoroafor, C, (2004). Cathodic protection as means of saving national asset. J. Corr. Sci. Tech., 1.1 (Special Edition), 1 - 6 .

Ovri, JEO and Ofeke, TBG, (1998). The corrosion behaviour of mild steel in marine environment. J. Sci. Eng. Tech., 5(\#2): 1117 - 1129.

Parasnis. DS, (1986). Principles of Applied Geophysics, $4^{\text {th }}$ edition, Chapman and Hall, London.

Rim-rukeh, A and Awatefe, JK, (2006). Investigation of soil corrosivity in the corrosion of low carbon steel pipe in soil. J. of Applied sciences research. 2(\#8), $466-469$.

http://www. testing-engineers. Com/ case study 1. html. 